\title{
Generic one, arbitrary PRO, and the first person
}

\author{
Friederike Moltmann
}

Received: 21 January 2005 / Accepted: 19 September 2006 /

Published online: 1 December 2006

(C) Springer Science+Business Media B.V. 2006

\begin{abstract}
The generic pronoun one (or its empty counterpart, arbitrary PRO) exhibits a range of properties that show a special connection to the first person, or rather the relevant intentional agent (speaker, addressee, or described agent). Generic one typically leads to generic sentences whose generalization is obtained from a first-person experience or action or else is meant to be immediately applicable to the relevant agent himself (in particular the addressee). I will argue that generic one involves generic quantification in which the predicate is applied to a given entity 'as if' to the relevant agent himself. This is best understood in terms of simulation, a central notion in some recent developments in the philosophy of mind and cognitive science (Simulation Theory): Generic one involves 'generic simulation', roughly 'putting oneself into the shoes of anyone meeting relevant conditions'. Formally, this means that generic one introduces a complex variable, consisting of an ordinary variable and a 'mode of presentation' of the relevant intentional agent, namely the property of being identical to that agent. Generic one, like other pronouns acting as bound variables, may also introduce just an ordinary variable. In both cases, the ordinary variable needs to be bound by a sentential generic operator.
\end{abstract}

Keywords Generic one - Arbitrary PRO - Genericity · Variables ·

Simulation $\cdot$ First person

I would like to thank Chris Peacocke for fruitful discussions at the initial stage of this work, in particular for pointing out the connection to Simulation Theory. I would furthermore like to thank Mike Martin, Dominique Sportiche, Robert Stalnaker, Ede Zimmermann, and audiences at the University of Amsterdam, Rutgers University, and especially the Institut Jean Nicod and the Ecole Normale Superieure in Paris for discussions.

F. Moltmann ( $ه)$

IHPST, 13, Rue du Four,

75006, Paris,

France

e-mail: fmoltmann@univ-paris1.fr 
The English pronoun one as in (1) leads to generic sentences of a certain kind:

(1) One can see the picture from the entrance.

In (1), one seems to stand for human beings in general, but at the same time it bears a particular relation to the intentional agent of the utterance, the speaker's self or the first person in the philosopher's sense of the term. ${ }^{1,2}$ Suppose the speaker is standing at the entrance, looking at the picture. In that case, an utterance of (1) is appropriate as an immediate expression of the speaker's own experience, while at the same time making a generalization. Other generic sentences such as People can see the picture from the entrance or A typical person can see the picture from the entrance would not have the same status: while they may make the same generalization, they do not serve as an immediate expression of the speaker's own experience. ${ }^{3}$

The fact that one as a generic pronoun bears a particular relationship to the first person is what makes its semantics especially interesting: intuitively, with generic one a speaker draws a generalization by applying the predicate to any (human) being as if that human being was himself, making both a generic statement and, in a way, reference to himself. This particular way of applying a predicate 'as if to oneself' involves a notion that has come to play a significant role in some recent developments in the philosophy of mind and cognitive science, namely the notion of simulation, or more precisely, what I will call generic simulation. By simulating others, an agent pretends to be those other people and thus can ascribe properties to them by self-ascribing those properties.

Generic one occurs in other kinds of contexts that in (1), in particular in deontic statements (as in One should not lie). But here too a first-person related application of the predicate is essential: in the case of deontic statements, the predicate is applied to entities 'as if to oneself' in order to allow an immediate use of such statements for the purpose of practical reasoning.

I will discuss a wide range of semantic data in which the first-person connection of generic one manifests itself and in which one distinguishes itself from other, more familiar generic noun phrases such as people, human beings, or a typical person. Often the peculiarities of generic one-sentences are displayed best in contexts in which one occurs in a sentence embedded under an attitude verb. This is because the meaning of one involves a first-person orientation that goes beyond a simple contribution to the truth conditions of sentences, which is less apparent in independent sentences. In independent sentences, though one may lead in more subtle ways to use-related differences and differences in the appropriate expression of mental states.

\footnotetext{
${ }^{1}$ The term 'first person' in this paper is used not so much in the grammatical sense, but rather in the philosopher's sense, on which it is understood as the 'self', the relevant intentional subject from his own point of view (see for example Perry, 1996).

${ }^{2}$ The generic pronoun one in English must be clearly distinguished from the numeral one (one apple) and the pronoun one as in everyone or one who does not understand this, which has the content of the noun person. A quick look at other languages shows that generic pronouns like one in English are not generally derived from or directly related to numerals or pronouns like one (e.g. German man, French on, Italian si). The analysis I develop will not establish any direct semantic connection either.

${ }^{3}$ Note that (1) does not require that the generalization made be based on the speaker's own experience, if the speaker is for some reason not able to do so. I will discuss this later in this paper. 
The paper gives an analysis of the generic pronoun one as used in British English, as well as its empty counterpart, arbitrary PRO. In American English generic one is increasingly replaced by other expressions such as you and we. But this should not distract from the main goal of this paper, which is not so much an analysis of the particular meaning of pronominal one, but rather to identify an important 'semantic strategy' that happens to be associated with one in British English and that is, or can be, associated in other languages or other varieties of English with expressions of different sorts. ${ }^{4}$

Before I discuss the properties of one that relate to the first person, I will address the issue of the semantic status of generic one as an NP, which is of somewhat independent interest.

\section{The semantic status of one as an NP}

As a very first approximation, generic one generalizes over conscious beings, often in a contextually restricted class. ${ }^{5}$ For example, one in (2) has a reading on which it ranges only over the students in a given class (to which the speaker belongs):

(2) One has to hand in the essay tomorrow.

The class of conscious beings one ranges over, moreover, generally 'but not always' includes the speaker as well as the addressee.

Generic one always leads to generic statements. Clearly, generic one does not correspond to a universal quantifier, but rather fares with other generic NPs in that it allows for exceptions and has 'modal force'; that is, it does not just quantify over actual entities. This is obvious when one-sentences are embedded under attitude verbs:

(3) a. John doubts that people can see the picture from the entrance.

b. John doubts that one can see the picture from the entrance.

c. John doubts that everyone can see the picture from the entrance.

4 The semantic strategy in question constitutes only one of several meanings of French on (which can also simply mean 'we') and German man (which also has the meaning of a certain use of 'they'). $O n$ and man are special also in that they can only occur in subject position. German, though, also has einem (dative) and einen (accusative), which have only the meaning of generic one.

The meaning of generic one is also only one meaning of Italian impersonal si (Chierchia, 1995).

${ }^{5}$ Generic one does not actually range over human beings, as seen by the acceptability of (ia) as opposed to (ib) or (ic):

(i)a. If one is a Martian, one is not susceptible to human disease.

(Safir, 2000)

b. ?If one is a horse, one eats hay.

c. ???If one is a box, one is put on the shelf.

This holds, contrary to common assumption, also for arbitrary PRO:

(ii)a. $\quad \mathrm{PRO}_{\mathrm{arb}}$ to be a Martian means that one is not susceptible to human disease.

b. $\quad \mathrm{PRO}_{\mathrm{arb}}$ to be an angel means $\mathrm{PRO}_{\mathrm{arb}}$ to be neither human nor divine.

The restriction thus is to conscious beings rather than humans. This will follow from the account I will develop: it is conscious beings more generally, not just human beings, that can be 'simulated' by an agent. 
In (3a), the focus of John's doubt can only be the overall generalization expressed by the that-clause. By contrast, the focus of John's doubt in (3c) may be that there are no exceptions to the generalization, which is impossible for (3a). Clearly, (3b) goes together with (3a) rather than $(3 \mathrm{c})$.

Generic one could not possibly be considered a term referring to a group or class, since it does not accept collective predicates:

(4) \# One does not know each other well.

More importantly, one cannot be considered a term referring to something like a kind-e.g. the kind human being (pace Safir, 2000). This can be seen from the fact that predicates like rare or widespread, which are generally indicative of kind reference, are impossible with generic one:

(5)a. \#One could become rare.

b. This kind of animal could become rare.

Generic one, we can thus say, acts as a variable ranging over individuals, a variable bound not by a universal quantifier, but rather by a generic quantifier that allows for exceptions and has itself modal force. Without going into any further detail about the nature of that quantifier, let us simply say it is the generic quantifier $\mathrm{Gn}$ as commonly used in the linguistic semantic literature on generic sentences (cf. Krifka, et al., 1995). ${ }^{6}$

Generic one can occur in, apparently, two distinct ways: [1] as a pronoun inducing genericity; and [2] as a bound variable, exemplified by the first and second occurrence of one in (6a) and (6b) respectively:

(6)a. One often loses one's belongings on a train.

b. One often thinks that one's mother is nice.

In embedded contexts, one may be ambiguous between the two readings, as in (7):

One often thinks that one should not eat meat.

Sentence (7) can either mean that a human being $x$ often thinks that $x$ should not eat meat or else that human beings often subscribe to general vegetarianism.

In both occurrences, generic one alternates with arbitrary PRO, the empty subject in the subject clause in $(8 \mathrm{a})$ :

(8)a. $\left[\mathrm{PRO}_{\mathrm{arb}}\right.$ to dance all night $]$ is fun.

Arbitrary PRO in fact appears to be the manifestation of generic one when an overt $\mathrm{NP}$, for syntactic reasons (such as Case assignment), is not possible. This is obvious not only from the fact that arbitrary PRO exhibits the same restriction to conscious beings and leads to generic sentences of the same sorts, but also from the fact that arbitrary PRO can act as the antecedent of bound-variable one (as in (8b)) as well as reflexive oneself (as in (8c)) and that it can be bound by the same generic operator as an occurrence of generic one in the same sentence, as in $(8 \mathrm{~d}):^{7}$

\footnotetext{
${ }^{6}$ Note that as such generic one-sentences need not make a generalization about entities, but may claim that a rule is in place (cf. Carlson, 1995; Cohen, 1999). This is the case with deontic one-sentences such as One should not lie.

${ }^{7}$ For the observation that arbitrary PRO acts as antecedent of the reflexive oneself see already Chomsky (1980).
}

Springer 
(8)b. $\quad\left[\mathrm{PRO}_{\text {arb }}\right.$ to walk one's dog] is fun.

c. $\quad\left[\mathrm{PRO}_{\mathrm{arb}}\right.$ to teach oneself] is often the most efficient way to learn.

d. $\quad\left[\mathrm{PRO}_{\mathrm{arb}}\right.$ to walk home] means that [one cannot afford a cab].

Generic one, like arbitrary PRO, can also alternate with the implicit argument of adjectives, such as the implicit agent of evaluative predicates:

(8)e. It is astonishing $\left[\mathrm{PRO}_{\mathrm{arb}}\right.$ to see the picture from the entrance].

f. It is nice when one takes a walk in the evening.

In $(8 \mathrm{e}, \mathrm{f})$, the same generic operator binds the implicit 'judge' of astonishing and nice and arbitrary $\mathrm{PRO} /$ generic one.

Even though genericity-inducing one can bind variables, it does not itself behave like a quantified noun phrase. In particular, it does not have to be in one of the syntactic positions a quantified NP has to be in (i.e., c-command the pronoun) in order to induce a bound-variable effect on another occurrence of one. This can be seen from the possibility of weak crossover in (9) as well as the 'donkey-sentence'like cases in (10):

(9) One's mother always gives one a birthday present.

(10)a. Every book that one has read as a child stays in some way in one's memory forever.

b. When one opens the book, one is struck by the quality of the paper.

c. If one is disabled, one gets special benefits.

The sentences in (10) at first sight seem to be parallel to the familiar 'donkeysentences' with indefinite NPs as in (11) (Heim, 1982; Kamp, 1981):

(11)a. Every book a child has read stays in his memory forever.

b. When a book is opened, it displays the quality of the paper.

c. If a person is disabled, she gets special benefits.

In (11a), we have a quantificational donkey-sentence, and in (11b) and (11c) conditional donkey-sentences. What is characteristic about donkey-sentences is that the quantifier the indefinite should stand for is unable to bind the variable represented by the pronoun, on any reasonable compositional analysis (Heim, 1982). One behaves like an indefinite able to induce a bound-variable effect on a pronoun (another occurrence of one) that cannot be bound by a quantifier that one (in its first occurrence) could stand for.

However, the similarity between the sentences in (10) and in (11) is misleading. There is a major difference between ordinary indefinite NPs and genericity-inducing one: unlike ordinary indefinites, genericity-inducing one is never able to act as an existential quantifier taking narrow scope with respect to a quantified NP in whose syntactic scope (or c-command domain) one occurs. Compare (12a) with (12b):

(12)a. Most books that one buys are not about oneself.

b. Most books that someone buys are not about himself.

Sentence (12b) has a natural reading on which someone takes narrow scope with respect to most books ('the majority of the books that somebody or other buys'), 
whereas such a reading is impossible in (12a). (12a) allows only for the reading that says that for any human being $x$, most books that $x$ buys are not about $x .^{8}$

An observation to the same effect can be made for (10a), where a little reflection makes clear that one can only be bound by a generic quantifier (allowing for exceptions) which takes wide scope over every book, rather than acting as an existential quantifier taking narrow scope with respect to every book or, equivalently, acting as a universal quantifier in the antecedent of the conditional (not allowing for exceptions). Of course, one also lacks an existential reading when it does not occur in the syntactic scope of another quantifier.

The fact that the generic quantifier always takes widest scope within a sentence with generic one indicates that one is in fact bound by a sentential generic operator rather than a quantifier of the sort introduced by a quantificational NP. Syntactically, this means that this generic operator is represented by an empty operator in sentence-initial position, the specifier position of $\mathrm{C}(\mathrm{SPEC}(\mathrm{CP}))$. The operator will also carry a feature of genericity, let's call it [+gn]. Thus we have (13) as the Logical Form of (12a):

$$
\left[\text { CP }\left[\operatorname{SPEC}(\mathrm{C}) \mathrm{O}_{[+\mathrm{gn}]}\right]_{\mathrm{i}}\left[\text { IIP most books that one } \mathrm{i}_{\mathrm{i}} \text { buys are not about oneself } \mathrm{i}_{\mathrm{i}}\right]\right.
$$

The same generic operator $\mathrm{O}_{[+\mathrm{gn}]}$ of course will be able both to bind occurrences of one and to control arbitrary PRO.

Occurrences of generic one are obligatorily bound by the generic operator. Unlike indefinites as in (14a), generic one is not able to introduce a variable that will be bound by an adverb of quantification, as seen in (14b).

(14)a. People sometimes are not talented enough to write great fiction.

b. One sometimes is not talented enough to write great fiction.

Sentence (14b) lacks the reading (14a) has, namely 'Some people are not talented enough to write great fiction. ${ }^{9,10}$ Formally this means that generic one as well as arbitrary PRO should carry the feature $[+\mathrm{gn}]$ as a formal agreement feature which will require those pronominal elements to be bound by a generic operator carrying that feature as well (but as an interpretable feature).

There seems to be only one exception to generic one having to be bound by a sentential generic operator, and these are NPs such as knowledge of oneself, reference to oneself, respect of oneself. Here the syntactic structure of the NP is one that requires not only the syntactic presence of an empty pronominal subject able to bind reflexive oneself (cf. Giorgi \& Longobardi, 1991), but also the presence of a

\footnotetext{
${ }^{8}$ The fact that someone in (11b) does not act like an existential quantifier rather than a bound variable is also known as the Proportion Problem, which posses serious difficulties for the Heim (1982)/Kamp (1981) account of indefinites.

${ }^{9}$ For the ability of adverbs of quantification to bind variables introduced by indefinites see Lewis (1975) and Heim (1982). For the observation that one cannot be bound by an adverb of quantification see also Safir (2000).

${ }^{10}$ However, for some reason, adverbs of quantification are possible in conditionals:
}

(i)a. When one is German, one usually does not need a visa to travel to the US.

b. When one likes Mozart, one almost always likes Schubert as well.

Why there is such a difference between adverbs of quantification in nonconditional and in conditional one-sentences remains to be explained. 
generic operator within the NP, which itself would have to obtain a clause-like structure.

Generic one thus has as one of its semantic functions the introduction of a variable that is obligatorily bound by a sentential generic operator. In addition to introducing a variable, though, genericity-inducing one also carries a certain sort of meaning that relates to the first person and is responsible for the restriction to conscious beings and the inclusion of speaker and addressee. Let me call this the first-person orientation of generic one.

In the course of this paper, I will propose that this first-person orientation should be represented as a particular, indexical second component of a complex variable that generic one introduces. For the time being, though, I will just take it to be represented by an interpretable lexical feature [+1st-ps] associated with occurrences of generic one. Such occurrences of generic one then carry two sorts of features: an uninterpretable feature [+gn] that requires one to be bound by a sentential generic operator and the interpretable [+1st-ps]-feature that it is responsible for a particular indexical interpretation.

Generic one can also have occurrences as a 'pure' bound variable, occurrences in which the lexical feature [+1st-ps] would not be present at Logical Form. These are occurrences of generic one of just the same sort as bound variable occurrences of indexicals like $I$ or you (cf. Kratzer, 1998), as in (15), where my acts as a bound variable:

(15) I am the only one that has done my homework.

In the case of generic one, pure bound variable occurrences include both occurrences that covary with another occurrence of generic one, such as the second occurrence of one in (16a), and occurrences that covary with the variable introduced by another quantifier, such as the quantifier not only one oneself in (16b), which as such binds the variable introduced by one's:

(16)a. Everyone one meets notices it when one has not slept in days.

b. It is good to know that it is not only one oneself that can lose one's keys.

In such occurrences, generic one will carry only the formal, uninterpretable feature $[+\mathrm{gn}]$ that requires it to be bound by an operator in SPEC(CP) carrying that feature as an interpretable feature.

Let us say, following Kratzer (1998), that pronouns only introducing bound variables are empty pronouns at LF, carrying no interpretable feature. Then the Logical Form of (6b) would be:

$$
\begin{aligned}
& {\left[\mathrm{CP}\left[\mathrm{O}_{[+} \mathrm{gn}\right]\right]_{\mathrm{i}}\left[\mathrm{IP}\left[\mathrm{NP} \text { one }[+\mathrm{gn}]\left[+\mathrm{Ist}^{\mathrm{st}}-\mathrm{ps}\right]\right]_{\mathrm{i}} \text { often thinks that }\left[\varnothing_{[+\mathrm{gn}]}\right]_{\mathrm{i}}{ }^{\prime} \mathrm{s}\right.} \\
& \text { mother is nice }]]
\end{aligned}
$$

It is only at the level of Phonetic Form PF, as Kratzer proposes, that empty pronouns will be spelled out, depending on which feature-carrying elements they are coindexed with. In particular, an empty pronoun carrying the formal feature [+gn] and coindexed with a pronoun carrying the $[+1 \mathrm{st}-\mathrm{ps}]$ feature will be spelled out as one, if that is possible, and identified as PRO otherwise. 
Arbitrary PRO will not be an empty pronoun of the same sort: it will carry both the $[+1$ st-ps]-feature and the [+gn]-feature and thus will have the first-person orientation as its lexical content. ${ }^{11}$

Let me now turn to the most interesting aspect of generic one, namely its firstperson orientation. It manifests itself foremost in the various restrictions on the semantic contexts in which generic one can occur.

\section{Strategies for licensing generic one in different semantic contexts}

Generic one is acceptable in only certain kinds of semantic contexts. For example, generic one is not possible with the same kinds of predicates that are unproblematic in other sorts of generic sentences. The following predicates, for example, are hardly acceptable with generic one, though they are fine in other generic sentences:

(18)a. ??One has a nose.

b. The typical person has a nose.

(19)a. ??One lives in a big city.

b. People live in a big city.

Sentence (18a) is impossible; whereas (18b) is acceptable as well as true. Also (19a) is hardly acceptable, whereas (19b) is fine, though false.

Other examples where generic one is unacceptable or highly unnatural are those in (20):

(20)a. ??One has a passport.

b. ??One has parents.

c. ??One breathes.

d. ??One is nervous.

e. ??One gets up in the morning.

Again those sentences are fine with other generic NPs, such as people or the typical person.

Given these data, the generalization seems to be that sentences describing characteristic properties, locations, psychological states, or habits are unacceptable with generic one. There are particular circumstances, though, under which generic one may become acceptable even in such sentences. For example, (19a) can be tolerated in a context in which living in a big city is considered some sort of general requirement, so that in fact (19a) would describe the fulfillment of that requirement.

11 Generic one thus differs from indefinites in several respects: unlike indefinites, it is not subject to a novelty condition (as it can be linked by an already present occurrence of generic one); nor does it exhibit quantificational variability. Furthermore, unlike other indefinites generic one does not occur in there-sentences, as was pointed out to me by an anonymous referee:

(i) $*$ There is one in the garden.

However, generic one fares with various other 'indefinites' that are obligatorily bound by a sentential operator, such as free choice any on Kadmon and Landman's (1993) account. See Kratzer (2006) for further discussion.

The Italian impersonal pronoun si seems another expression that introduces a variable without being able to be bound by an existential quantifier (Chierchia, 1995). Italian si has a quite different meaning from English one, though. 
(19a) just cannot be used for making a simple statement about people in general or about a particular class of people (which includes the speaker). As a description of a fulfillment of a general requirement, the other examples, (19a) and (20a-e), may become acceptable as well.

Thus, it is not obvious how to draw an empirical generalization about predicates with which generic one is unacceptable. Giving a unified characterization of the kinds of predicates with which generic one cannot occur seems in fact impossible also for the following reason: in certain complex sentences generic one does not impose any restrictions at all. First, when generic one occurs in the antecedent or the consequent of a conditional, it does not impose any semantic restrictions on the predicate whatsoever:

(21)a. If one lives in a big city, one lives in a city.

b. If one has a nose, one can breathe.

c. If one is nervous, one should take a tranquillizer.

Second, bound-variable occurrences of generic one are exempt from semantic restrictions:

(22)a. One sometimes thinks that one lives in a big city, when in fact one lives in a minor town.

b. It can happen that one dreams that one does not have a nose.

Thus, rather than trying to give a unified characterization of the predicates that exclude generic one, a better question to ask is: under what circumstances is generic one possible? What are the 'semantic strategies' that license generic one, that is, what are the underlying semantic conditions that make generic one acceptable with certain predicates or readings of predicates, or with certain kinds of compositional semantic processes (such as are involved in conditionals)? In answering this question, three important 'semantic strategies' can be distinguished that license generic one:

Strategy 1: Inference from the First Person

Generic one is licensed in a (simple) sentence establishing a generalization based on a first-person application of the predicate.

Strategy 2: Inference to the First Person

Generic one is licensed in a (simple) sentence stating an (already established) generalization that is to allow for an immediate application to the first person in the reasoning relevant in the context of discourse.

Strategy 3: Inference from the Simulating Self

Generic one is licensed in a sentence expressing an inference from the first person pretending to meet certain conditions.

In what follows, I will first focus on Strategy 1, by discussing the various semantic contexts that make use of it and developing on that basis a formal semantic analysis of generic one. I will then discuss Strategy 2, showing that the various semantic contexts that make use of it can be accounted for on the basis of the same semantic 
analysis. Finally, I will introduce Strategy 3, which is a sort of extension of Strategy 1 and applies in particular to conditionals. ${ }^{12}$

\section{Strategy 1: Inference from the first person}

Our initial example, repeated below as (21), is a typical example of Inference from the First Person:

(23) One can see the picture from the entrance.

As was said already, (23) has a natural reading on which it expresses a generalization of the speaker's own, perhaps one-time experience, where the speaker can assume that this experience is generalizable (knowing that his physical constitution is normal, etc).

This reading, though clearly the most natural one, is not the only reading possible for (23), though. For (23) to be true, the speaker need not have seen the picture himself. Even if he is unable to see the picture, he can be justified in claiming (23). What goes on in such cases, I'd like to suggest, is something quite similar to the first case: the speaker puts himself into the position of 'the normal person' who can see the picture, or in other words, the speaker simulates anyone meeting normal conditions.

There is a range of semantic contexts in which generic one can lead to such an expression of generality on the basis of a first-person experience or perhaps simulated experience. The most important ones are sentences expressing physical possibilities or experiences in certain types of situations.

\subsection{Sentences expressing physical possibility}

The first semantic context consists of simple sentences expressing physical possibility. (23) is of course an example. The sentences below are further cases in point:

(24)a. One can die from eating these mushrooms.

b. One can open the bottle with one hand.

c. One can easily jump over the fence.

As in the case of (23), with sentences expressing physical possibility in general, there are readings available in which the generalization expressed is not based on a first-personal experience. Such readings are made explicit in the following examples:

(25)a. One can get cancer from too much sun (though I never did).

b. One can prove this theorem (though I cannot).

Example (25a) does not illustrate Strategy 1, but Strategy 2, which I will discuss later. To anticipate, I will maintain that even in such cases, generic one is licensed because of a first-person application of the predicate: here it is an envisaged possible

12 Certain disjunctions as well, namely those of the form $\mathrm{p} \mathrm{v} \neg \mathrm{p}$, suspend the relevant restrictions:

Either one lives in a big city or one does not live in a big city.

This is best treated as a case of Strategy 2: (i) expresses an independently established rule, an instance of a law of logic, with an envisioned first-person application. 
first-person application in the sense that the reason one is used in (25a) is to trigger an inference of the form 'I can get cancer from too much sun', an inference not so much meant to be made on the part of the speaker, but rather more likely on the part of the addressee were he to accept the speaker's utterance of (25a). The firstperson application here is not the source of the generalization expressed, but rather an envisaged inference from an independently established generalization.

The natural context for uttering (25b) is likely to be yet a different one: here the first-person connection may consist in expressing the fact that a human being such as the speaker himself is in principle able to solve the problem (the modality involved in can thus is not the same as that involved in cannot). Note that otherwise (25) would not even be a generic sentence, but rather express existential quantification ('Someone can prove the theorem').

The strategy of Inference from the First Person is particularly obvious when a generic one-sentence like (23) is embedded under an epistemic predicate:

(26)a. John found out that one can see the picture from the entrance.

b. John confirmed that one can see the picture from the entrance.

c. Everyone confirmed that one can see the picture from the entrance.

For (26a) to be true it is sufficient that John has had the experience of seeing the picture from the entrance. Similarly, for (26b) to be true all John needs to have done is to have gone to the entrance and have seen the picture from there. The same holds for $(24 c)$, where each of the people in question bears the first-person connection to one. Universally quantified and other generic sentences behave quite differently. The examples in (26) differ significantly from those in (27):

(27)a. John found out that people can see the picture from the entrance.

b. John confirmed that people can see the picture from the entrance.

c. Everyone confirmed that people can see the picture from the entrance.

In $(27 \mathrm{a}, \mathrm{b})$, John has to have made sure in other ways that people other than himself can see the picture from the entrance, and similarly for $(27 \mathrm{c})$.

\subsection{Other semantic contexts involving inference from the first person}

There are other semantic contexts than those expressing physical possibility that allow for generic one by making use of Strategy 1. One such context consists of sentences describing experiences in certain types of situations:

(28)a. One feels tired after such a long day.

b. One gets really upset when something like this happens.

The relevant (and most natural) reading of (28a) is of course one on which the speaker, by uttering the sentence, expresses his own state of tiredness. The speaker at the same time generalizes by abstracting a type of situation from the situation he finds himself in. This reading obviously displays the same sort of firstperson-based genericity as sentences expressing physical possibility. The same holds for $(28 b)$.

The use of sentences like (28a, b) for an immediate description of a first-person experience is particular clear when such sentences are embedded under certain attitude verbs: 
(29)a. Sometimes I have the impression that one cannot get enough sleep after so much work.

b. John suddenly knew how one feels after a major victory.

The embedded one-sentences in (29) naturally serve as direct descriptions of a firstpersonal psychological state, though of course the generalizing force is there as well. (29a) and (29b) thus differ markedly from $\left(29^{\prime} a\right)$ and $\left(29^{\prime} b\right)$, where the psychological state takes as its immediate source third-person observations, or else has a derived content, obtained only inferentially from a first-person experience:

$\left(29^{\prime}\right)$ a. Sometimes I have the impression that an ordinary human being cannot get enough sleep after so much work.

b. John suddenly knew how people feel after a major victory.

Note also that someone very ill can point out another person's lack of sensitivity toward him by uttering (30a), whereas (30b) does not ask for empathy in the same way:

(30)a. You do not know how one feels facing a ten-year prison sentence!

b. You do not know how people feel facing a ten-year prison sentence!

To give another example making the same point, a speaker can express his loss of words by exclaiming (31a), but not really by exclaiming (31b):

(31)a. What the hell can one say in such a situation?

b. What the hell can people say in such a situation?

Sentences of the sort in (28) must mention types of situations rather than specific situations. Thus, (28a) and (28b) — for at least a number of speakers-are better than (32a) and (32b), where reference to a particular situation is made:

(32)a. One feels tired after talking to Mary today for three hours.

b. One feels upset after this has happened.

There are speakers for whom (32a) and (32b) are perfectly acceptable, but they appear to be fewer than those for whom $(28 \mathrm{a}, \mathrm{b})$ are. For such speakers, the sentences in $(33 \mathrm{c}, \mathrm{d})$ are also fine (though they are judged rather upper-class English):

(33)a. One thought that Paris was beautiful.

b. One thinks the rain must stop at some time.

c. After all these efforts, one would think that John should be able to pass the exam.

d. One is fascinated watching this carnival.

While at first sight such examples do not seem to describe any real generality at all, arguably even here the speaker generalizes, in the sense that his experience is presented as one arising for anyone in the situation in question.

Inference from the First Person may also relate to the frequency of the occurrence of experiences of a certain sort. Thus, the frequency claim made in (34) is naturally based on a limited number of the speaker's own experiences:

(34) Sometimes one receives strange advertisements in the mail.

By contrast, the inductive frequency claim made in (34') will have to be based on a sufficient number of third-person experiences:

(34') Sometimes people receive strange advertisements in the mail. 
Arbitrary PRO as well, of course, can be licensed by Strategy 1, for example in evaluative sentences describing a general evaluation arising from a first-person experience:

$$
\text { It is great }\left[\mathrm{PRO}_{\mathrm{arb}}\right. \text { to see you]. }
$$

Example (35) serves as an immediate expression of the speaker's own evaluation of seeing the addressee, while at the same time constituting a generalization.

\subsection{A simulation-theoretic approach}

Strategy 1 consists in generalizing on the basis of a first-person experience (or perhaps simulated experience), by assuming certain conditions of normality to obtain. This method of generalizing is best viewed as what I will call generic simulation. The term 'simulation' itself is the core term in a more recent approach in philosophy of mind and cognitive science, namely Simulation Theory (cf. Goldman, 1989, 1995; Gordon, 1986, 1995a, 1995b; Heal, 1986). Simulation Theory is a particular theory about how people ascribe propositional attitudes to others and predict or explain their behavior. Simulation Theory, and the notion of simulation itself, is best understood against the background of the traditional view about the ascription of attitudes and the explanation/prediction of actions of others, namely what is called the Theory Theory. On the Theory Theory, an agent attributes propositional attitudes to others, explains their past actions, and predicts their future actions on the basis of a tacit theory about other people's behavior, a theory based in particular on observing how other people behave. The Theory Theory is essentially a third-person approach: propositional attitudes and actions are attributed directly, on the basis of the theory, to another person. Simulation Theory contrasts with the Theory Theory in that it is fundamentally a first-person approach. According to Simulation Theory, third-person ascriptions of attitudes and explanations and predictions of actions are based on first-person ascriptions: on the basis of 'putting oneself in the other person's shoes', that is, of pretending to be that person or taking the other person's point of view-in other words, on the basis of simulating the other person.

First-person-based genericity is genericity based on simulation, rather than theory about others. More precisely, first-person-genericity is based on generic simulation: a property is attributed to anyone in the relevant class on the basis of the speaker's attributing that property as if to himself, while abstracting from the peculiarities of his own situation. Generic simulation is somewhat different from the kind of simulation discussed in the literature on Simulation Theory. The simulation-theoretic literature has concerned itself only with specific simulation, the attribution of properties to a specific person in whose situation the agent puts himself. In the case of generic one, the relevant intentional agent generalizes from his own situation, abstracting from features of his situation that are particular to himself. It is in this way that the agent can take the point of view of each member in the relevant set. The agent thus does not need to make any adjustments to adopt another person's point of view, but simply needs to abstract from what is particular to his own situation.

\subsection{The account formally}

The formal semantic analysis that I propose to account for the generic simulation involved in generic one is actually a fairly simple one. The analysis itself in fact does 
not involve any such notion as simulation or pretense. It involves simply a complex variable, an ordered pair which consists of an 'ordinary' variable and a 'mode of presentation', the latter roughly meant to stand for the relevant intentional agent's 'self'.

Intuitively, the 'ordinary' variable concerns the truth conditions of a onesentence, whereas the mode of presentation is to govern the applicability of predicates, providing as such either the epistemic basis or the practical purpose for applying the predicate. Let us take the mode of presentation to be a property of some sort. Then, if we have a complex variable $<x, M>$ as introduced by generic one, a predicate $P$ should be taken to be true of $\langle x, M\rangle$ just in case $P$ is true of $x$ as if it was $M$.

The crucial question now is: what is this mode of presentation $M$ of the relevant intentional agent's self? When a propositional content involves reference to the intentional agent's 'self', then we have in fact a propositional attitude (or speech act) de se, a 'self-locating propositional attitude'. Therefore a few words are needed about attitudes de se in general. One main criterion characteristic of a de se interpretation of a pronoun is immunity to error through misidentification (cf. Evans, 1982; Shoemaker, 1968). That is, roughly, a pronoun interpreted de se cannot possibly fail to refer to the entity the speaker wants to attribute the predicate to, as is possible with terms whose reference is mediated by description. To illustrate a de se interpretation, let us take the well-known example of Castaneda $(1966,1967)$ of an amnesiac war hero who has lost all his memory and fails to identify himself with that famous war hero he is reading about in a library. In that case only (36a), which allows for a de re interpretation of $h e$, would be true, but not (36b), which describes an attitude de se:

(36)a. The war hero thinks that he is a hero.

b. The war hero thinks that he himself is a hero.

It is generally agreed that in attitudes de se, the agent need not have any conception of himself: the self does not play a role as an entity in a propositional attitude de se, not even as a mode of presentation. This is precisely what is avoided by an account of attitudes de se such as Lewis (1979). On Lewis's account, attitudes de se involve not a proposition, but a property as their content. Attitudes de se then consist in the self-ascription of a property to the relevant agent. This corresponds to a formal semantic analysis on which an attitude verb like expect takes a property, not a proposition, as an argument (cf. Chierchia, 1990). Thus (37a), where controlled PRO has an obligatory de se reading, would be represented as in (37b), not as in (37c), which would represent an interpretation de re: ${ }^{13}$

\footnotetext{
${ }^{13}$ Such a division between two semantic aspects of a term is not entirely unfamiliar. Certain uses of terms even in unembedded contexts also seem to involve what one can be call modes of presentation, in addition to reference (see Forbes, 1997 and the discussion in Saul, 1997). Reference to a mode of presentation can be made explicit, it seems, with as-phrases or attributive constructions, as in (ia, ib).

(i) a. John as a poet makes little money, John as a banker makes lots of money.

b. I like John the poet, but not John the banker.

A simple account of such cases would be to take the terms in (i) not to stand for a simple object, but for pairs consisting of an object and a property, that is, John the poet would stand for the pair $<$ John, $\lambda x[\operatorname{poet}(\mathrm{x})]>$.

Unlike with generic one, though, the property that is the mode of presentation must in fact hold of the referent of the term: for (ia) and (ib) to be true John must be both a poet and a banker. Examples such as (ia) and (ib) therefore are not necessarily independent evidence for the account of generic one that I have proposed.
} 
(37)a. John expects [PRO to win].

b. $\operatorname{expect}(\operatorname{John}, \lambda x[\operatorname{win}(\mathrm{x})])$

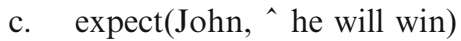

Higginbotham (2003) has recently argued for an account according to which a de se interpretation does in fact involve reference via a description and thus does go along with a mode of presentation, namely that of being the agent of the intentional act or state in question (e.g., a belief state or state of expectation). On Higginbotham's proposal, (37a) would have the analysis in (38):

$$
\left.\exists \text { e expect(e, John, ^ } \mathrm{e}^{\prime}\left[\operatorname{win}\left(\mathrm{e}^{\prime}, \operatorname{agent}(\mathrm{e})\right)\right]\right)
$$

That is, according to (38), the expectation relation holds between an event of expectation $e$, John, and the property of being an event of winning by the intentional agent of $e$. This account of attitudes $d e$ se thus provides a mode of presentation that could be used as the second component of the complex variable introduced by generic one. However, Higginbotham's proposal as such is rather problematic: it presupposes that the agent of the attitude de se always conceives of that attitude as an object and thus is conscious of it, since he makes reference to himself as the agent of the mental act or state involved. Attitudes de se then would always go along with a higher-order attitude about the attitude de se. Attitudes such as beliefs de se, however, seem much simpler, not involving a reflection upon the mental state itself. The point is expressed well by Rosenthal (2003, p. 339): "A thought about oneself, as such, refers to the individual that thinks that thought, but its content does not explicitly describe one as the thinker of that thought... Reference to the thinker, as such, is mediated not by descriptive content, but by the tie the essential indexical [i.e. de se pronoun] tacitly forges between a thought's content and its mental attitude." In other words, it is the attitude itself that is constitutive of de se, which is what is captured by Lewis's account. By contrast, on Higginbotham's account, de se is constituted by reflection upon an already given mental state.

There are other problems for Higginbotham's account. One of them, acknowledged by Higginbotham himself, is that propositional contents of propositional attitudes de se can be shared by different agents, validating the following inference:

(39) John believes that he himself is a hero.

Bill believes that he himself is a hero.

John and Bill believe the same thing.

(40) John believes what Bill believes too.

The inference in (39) does not hinge on the use of the expression the same thing: (40) would be an equally valid conclusion.

Higginbotham's proposal is moreover difficult to carry over to generic onesentences. Generally, the first-person orientation of generic one should not have to be linked to a particular intentional event, but should be applicable to whatever the relevant intentional state or event and relevant intentional agent is. First, as with attitudes de se, different agents entertaining the content of a single one-sentence intuitively share the same propositional content, as indicated by the validity of the following inference:

(41) John thinks one can see the picture from the entrance.

Bill thinks that one can see the picture from the entrance.

John and Bill think the same thing. 
Second, the first-person orientation is not necessarily related to the speaker and thus the utterance event, but may be intended for the addressee, in particular with Strategy 2, which is meant to trigger practical reasoning on the part of the addressee. This very same point is brought out also by embedding a one-sentence under certain speech act verbs, such as the verb remind, which expresses both an agent's act of assertion and the resulting state of acceptance on the part of the addressee:

Walking together, John reminded Mary that one should not cross the street at a red light.

Remind is a verb that expresses a complex event consisting of an assertion on the part of the subject referent and an act of acceptance on the part of the object referent. The first-person orientation of one relates to both events. ${ }^{14}$

Lewis's account of attitudes de se is a more promising point of departure. But how, given that account, should the first-person orientation of generic one be construed formally? Lewis himself, in a way, provides the answer. On Lewis's view, all ascriptions of properties to individuals take place under some description, which is a relation of acquaintance. Self-ascription of a property is the ascription of a property to oneself under the relation of identity, 'a relation of acquaintance par excellence' (Lewis, 1979). The first-person orientation of generic one can then be construed as the property $\lambda \mathrm{x}[\mathrm{x}=\mathrm{y}]$ (with ' $\mathrm{y}$ ' being the variable corresponding to the relevant agent). Thus, (23) would have the analysis in (43a):

(43)a. Gn $x$ can see the picture from the entrance $(<x, \lambda z[z=y]>)$

More precisely, generic one-sentences such as (23) will themselves express a property, as in (43b):

(43)b. $\quad \lambda y[$ Gn $x$ can see the picture from the entrance $(<x, \lambda z[z=y]>)$

An assertion involving such a property is then to be understood as an assertion which, once accepted by the addressee (as it is intended to be), will lead to an attitude of the addressee that consists in the self-ascription of that property to the addressee himself. It is in this way that the first-person orientation of generic one will relate to the second person. An assertion whose content is a property can be evaluated as true or false only relative to the person accepting the assertion.

\subsection{Generic one and de se}

Given that generic one leads to propositional contents de se, one might think that generic one should necessarily go along with a de se interpretation itself. But this is not so for a bound-variable occurrence of generic one, such as the second occurrences of one in (44a) and (44b):

\footnotetext{
${ }^{14}$ Another, though perhaps solvable problem for Higginbotham's account are logophoric occurrences of one in sentences embedded under nouns referring to kinds of events:

(i) The claim that one can see the picture from the entrance has rarely been made.

Sentence (i) is obviously about a kind of event, rather than a particular event, a kind whose surface instances are events of the sort 'John's claim that one can see the picture from the entrance.' One here would need to involve the particular events, rather than the event type, and it is hard to see how that should be possible.
} 
(44)a. It is not only one oneself that notices it when one has gained a lot of weight.

b. Every friend one meets notices it when one has gained a lot of weight.

Examples (44a) and (44b) have implications of the form 'There is some d such that for a given value $\mathrm{d}$ of one, $\mathrm{d}$ notices that $\mathrm{P}$ holds of $\mathrm{d}^{\prime}$," which of course is an attitude de re.

The absence of a de se reading can be seen even better from a variation on Chomsky's contrasting examples in (45) (cf. Fodor, 1975):

(45)a. Only Churchill remembers PRO giving the speech.

b. Only Churchill remembers his giving the speech.

Example (45a), which describes an attitude de se, is true, but (45b), which does not, is false. (45a) intuitively describes an event 'from the inside', whereas (45b) describes it 'from the outside'. In comparing (46a) and (46b), we see that the same contrast holds for PRO and bound-variable one:

(46)a. If one gives a speech, noone but oneself can remember PRO giving that speech.

b. If one gives a speech, noone but oneself can remember one's giving that speech.

While (46a) can only be true, this is not so for (46b).

It is not surprising that a bound-variable reading of generic one does not require a de se reading: a bound-variable reading should arise on the basis of an empty pronoun, devoid of any lexical content.

\section{Strategy 2: Inference to the first person}

Strategy 2 for licensing generic one does not start out with a particular experience of the speaker, but rather with a generalization that has been established independently. This generalization, however, is presented with the intention to be at least potentially applied in a first-person way by the speaker or, more likely, the addressee, or both. As with Strategy 1, there is a range of contexts in which generic one can be licensed by the second strategy.

\subsection{Deontic and epistemic sentences}

Most importantly the second strategy is used in deontic sentences:

(47)a. One is not allowed to enter the room.

b. One should not lie.

c. One should be respectful toward the elder.

Examples with arbitrary PRO are especially those with infinitives embedded under evaluative or deontic predicates and with indirect questions as below:

(48)a. It is important [ $\mathrm{PRO}_{\text {arb }}$ not to enter the room].

b. $\left[\mathrm{PRO}_{\text {arb }}\right.$ to take the exam] is obligatory.

(49)a. The tailor knows what $\mathrm{PRO}_{\text {arb }}$ to wear at one's own wedding.

b. John knows how $\mathrm{PRO}_{\text {arb }}$ to behave. 
Whereas with Strategy 2, the speaker's own experience leads to the generalization expressed by the one-sentence, in these cases the speaker presents an internalized but already established generalization, a law, general requirement, or general recommendation. The generalizations expressed in (47) crucially play a role in the speaker's reasoning for his actions, or better are meant to play a role in the addressee's reasoning. For example, if the addressee accepts (47a), then this will likely prevent him from entering the room. That is, deontic one-sentences are generally uttered with the intention that they play a future role as premises in the addressee's practical reasoning.

The reason why generic one-sentences using Strategy 2 are so suited for governing an agent's practical reasoning is that they allow for an immediate first-person application by anyone who accepts them.

Unlike generic one-sentences using Strategy 1, generic one-sentences using Strategy 2 permit inferences to the first as well as the second person. That is, from the truth of (50a), we can generally infer both (50b) and (50c):

(50)a. One is not allowed to enter the room.

b. I am not allowed to enter the room.

c. You are not allowed to enter the room.

There are two qualifications to be made, though. First, generic one-sentences can be used in such a way that the speaker identifies with a group of people not including himself:

(51) One has to hand in the essay today. (teacher to students)

Second, there are 'logophoric' uses of one, that is, uses in which not the speaker but the intentional subject of the described attitude or speech act plays the role of the first person to which one relates:

(52)a. The politician told his fellow Americans that one should abstain from French products.

b. Hans believes that one needs a passport to travel to France.

If (52a) is uttered by a Frenchman, then the group one covers obviously excludes him. Similarly for (52b), uttered by a Frenchman as a report about a German citizen's belief.

We have already seen that sentences expressing physical possibility may also make use of Strategy 2. One in (25a), for example, seems to be licensed by its function in practical reasoning whose conclusion is the addressee's (or speaker's) intention to stay away from too much sun.

Also, certain attitude reports make use of Strategy 2. A relevant observation in that regard is that generic one-sentences are possible only with know, not think or other episodic factive attitude verbs:

(53)a. One knows that John is unreliable.

b. ?One thinks that John is unreliable.

c. ??One found out that John is unreliable.

Obviously, the crucial parameter is not factivity, but rather whether the sentences express general knowledge, that is, whether they express an already established and reliable piece of information which the speaker or addressee can make use of in his practical reasoning. Thus, if the speaker or the addressee accepts (53a), then the 
inference to 'I know that John is unreliable' is immediate and can govern the agent's decisions and actions in regard to John. ${ }^{15}$

One-sentences using Strategy 2 are targeted at possible actions on the part of the relevant intentional agent. They naturally act as premises for practical reasoning, that is, reasoning whose conclusion is an action (or at least the description of an action) on the part of the relevant agent. To make this more precise, consider a typical practical syllogism, involving the first person:

$$
\begin{aligned}
& \text { I intend to do E. } \\
& \text { I think that unless he does (I do) X, he cannot (I cannot) bring about E. } \\
& \text { I do X. }
\end{aligned}
$$

By including a deontic condition, this basic practical syllogism can be extended by making use of generic one:

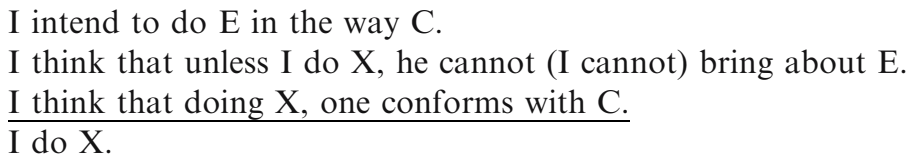

Generic one is justified in sentences using Strategy 2 because such sentences are meant to lead to inferences, in particular practical inferences, in which reference to the first person is fundamental and irreducible. One-sentences are the only sentences truly suited for that purpose: they express generality and imply an immediate application to the first person (and, once accepted, of course also to the second person).

Some other use-theoretic differences between one-sentences and universally quantified and ordinary generic sentences stress the same point. Consider:

(56)a. One is not allowed to enter the room.

b. Noone is allowed to enter the room.

(57)a. In this neighborhood, one drives a mercedes.

b. In this neighborhood everyone drives a mercedes.

c. In this neighborhood, residents drive a mercedes.

(58) I should drive a mercedes.

In order to prevent the addressee from entering the room, a speaker would most naturally utter (56a), rather than (56b). (56b) may involve an implicit contextual restriction that will preclude the addressee. Similarly, (57a), but neither (57b) nor (57c), seems to imply (58).

Laws and general advice are in fact typically formulated using generic one. The reason is that generic one carries both general force and a first-person orientation. A deontic generic one-sentence commits an agent who accepts it to act in certain ways, having made the sentence a premise in his practical reasoning.

The first-person orientation of one-sentences using Strategy 2 can also be seen from the suitedness of generic one for the expression of practical knowledge as in (59a), where again generic one could not be replaced by another generic NP, as in (59b):

15 Note that say and believe as well can be acceptable in one-sentences:

(i) One believes that John was involved in the crime.

Obviously believe leads to a less reliable antecedent for practical reasoning. 
(59)a. I know how one can use the metro without having to pay.

b. I know how people can use the metro without having to pay.

In the expression of practical knowledge, generic one and arbitrary PRO are equally suited, as seen in the equivalence between (60a) and (60b) and between (61a) and (61b), which contrast with (60c) and (61c) respectively, the latter lacking an immediate first-person application:

(60)a. I know how one should dress.

b. I know how $\mathrm{PRO}_{\text {arb }}$ to dress.

c. I know how people should dress.

(61)a. I know how one can open the bottle.

b. I know how $\mathrm{PRO}_{\text {arb }}$ to open the bottle.

c. I know how people can open the bottle.

4.2 Sentences describing future or past events, as a fulfillment of a 'script', plan, instruction

Generic one can occur in another semantic context using Strategy 2. This context, at first sight, differs from the ones so far considered in that it involves the description of a particular episode rather than a generalization:

(62)a. Later, one went to church, then one went to the reception, and finally one danced all night.

b. One goes to church later on.

Upon reflection, though, it is clear that these examples use Strategy 2 as well: (62a) and (62b) do not simply describe events, but rather events insofar as they are fulfillments of a condition, a plan, or a 'script. Thus, (62a) implies that someone planned that the guests went dancing at the end of the wedding. It cannot be meant as a description of what happened spontaneously. The sentences in (62) in fact are best viewed as descriptions of practical conclusions with deontic generic one-sentences as premises.

These intuitions can be brought out further by embedding such one-sentences under attitude verbs. Compare (63a) and (63b):

(63)a. John is satisfied that later one went to church.

b. ??John discovered/noticed that later one went to church.

Sentence (63a) is fine because it is a report about a mental state of satisfaction concerning the fulfillment of a plan. By contrast, (63b) is strange, since the fulfillment of a plan as such cannot be the object of mere empirical observation.

\section{Strategy 3: Inference from the simulating self}

A third strategy of licensing generic one, a strategy closely related to Strategy 1, is involved in conditionals: 
(64)a. If one is young, one has lots of energy.

b. If one has a nose, one can smell.

c. If one has an exam, one gets nervous.

d. If one is 2 meters tall, one is taller than John.

As was noted earlier and is illustrated here again, both in the antecedent and in the consequent of conditionals predicates are acceptable with generic one that are impossible in nonconditional sentences.

Why is generic one possible in conditionals without imposing any semantic restrictions on the predicate? I will argue that this follows simply from the analysis of conditional one-sentences in (65) that the present account would give them:

$$
\text { Gn } x(P(x, \lambda z[z=y]) \text { à } \mathrm{Q}(\mathrm{x}, \lambda \mathrm{z}[\mathrm{z}=\mathrm{y}]))
$$

That is, the occurrence of one introduces a complex variable whose first component will be bound by the generic operator and whose second component represents the 'first-person orientation. (65) says that for any $x$, if $P$ were to hold of $x$ as if it were to hold of the intentional agent himself, then $Q$ would hold of $x$ as if it were to hold of the intentional agent himself.

It is not difficult to see, given (65), why generic one is acceptable in conditionals: according to (65), the intentional agent simulates anyone having the property $P$, and it is said that under such pretense the agent would also have $Q$. The first-person orientation of generic one allows an agent to verify a generic conditional just on the basis of himself pretending to have the antecedent property, rather than having to involve other people as well. The first person-orientation of generic one in conditionals thus serves the purpose of an easy verification of conditional sentences.

This account of conditional generic one-sentences receives support from an independently motivated view of conditionals themselves. A common view about (indicative) conditionals is that conditionals involve hypothetically adding the antecedent to one's present state of accepted information and then verifying that the consequent follows from the resulting information state (Gaerdenfors, 1986; cf. Ramsey, 1931). Given this view, the hypothetical addition of the antecedent to one's stock of beliefs, the attitude of acceptance, is, as Recanati (2000) has emphasized, a form of simulation: it is simulated belief. Thus, according to the view in question, indicative conditionals as such involve a form of simulation. On the present account, it is just that the agent engages in generic simulation as well, identifying himself with anyone meeting the condition expressed by the antecedent.

A particularly interesting feature of conditional generic one-sentences is the choice of the mood of the antecedent. First, let us note that the speaker need not fulfill the condition expressed by the antecedent and this may be obvious, as, let us say, in $(66 \mathrm{a}, \mathrm{b})$ :

(66)a. If one is disabled, one gets special benefits.

b. If one is a Martian, one is not susceptible to human disease.(Safir, 2000)

In this respect, the antecedent of conditional generic one-sentences differs from the contextual restriction of nonconditional one-sentences, which generally has to include the speaker, as in (67):

(67) One gets special benefits. 
Thus, with indicative conditional one-sentences, an agent does not just abstract from the particularities of his own situation, but rather may have to take the point of view of a different situation, one in which the antecedent of the conditional is true, a situation that may be more specific or different from the one he actually considers himself to be in. What is interesting is that in the latter case, conditional one-sentences require no counterfactual mood, but are perfectly fine with the indicative.

The choice of indicative mood in apparently counterfactual conditional one-sentences supports one particular view of simulation. More precisely, there are two distinct views of simulation, namely that of Goldman and that of Gordon, and the phenomenon in question gives strong support for the latter.

On Goldman's (1989, 1995a, 1995b) view, an agent, when simulating another person, puts himself into the other person's situation and sees what he himself would do or what mental states he would be in, under those circumstances; only then will he attribute that same behavior or those attitudes to the other person. On that view, one would expect the subjunctive in sentences such as $(66 \mathrm{a}, \mathrm{b})$. the agent counterfactually puts himself into the situation of anyone meeting certain conditions and then sees whether he would in that situation also satisfy the consequence.

On Gordon's (1986, 1995a, 1995b) view, an agent, when simulating another person, 'imaginatively transforms himself into the target', by taking directly the perspective of the other person, in order to predict the behavior of that person or to attribute mental states to him. On that view, the simulator does not try to see how he himself would be in the other person's situation, but rather focuses on how the world would be from the very perspective of that other person. If we take Gordon's view of simulation and apply it to conditionals, then obviously the agent's own situation will play no role when the agent takes the position of anyone meeting the conditions of the antecedent. Rather, the agent identifies himself directly with anyone meeting the conditions of the antecedent, in order then to verify that the consequent is true in that situation as well. Therefore no counterfactual mood is expected. The behavior of conditional generic one-sentences thus gives strong evidence that the kind of simulation taking place in the semantics of generic one is that of Gordon rather than Goldman. $^{16}$

Generic one is also possible, though, in counterfactual conditionals:

If one were a Martian, one would not be susceptible to human disease.

The question of course is, why is the subjunctive mood used when even in conditionals the speaker needs to satisfy the conditions given by the antecedent? In counterfactual conditionals, it appears, one is associated with a contextual restriction that is incompatible with the counterfactual condition expressed by the antecedent. By contrast, in the case of indicative conditionals, there is either no contextual

\footnotetext{
${ }^{16}$ Note also that in conditional one-sentences, the antecedent of the conditional is not on a par with the possible contextual restriction of one. This is shown in the contrast between (ia), which is subject to restrictions on the predicate, and (ib), which is not:
}

(i)a. ??One is susceptible to human disease.

b. If one is human, one is susceptible to human disease.

The consequent of a conditional does not exhibit the same restrictions as are exhibited by nonconditional one-sentences. Rather, conditional one-sentences are possible regardless of the nature of the predicate in the consequent. This means that conditional one-sentences could not possibly be analysed in such a way that the antecedent provides the restriction of the generic operator. 
restriction or else the contextual restriction is not in conflict with the content of the antecedent. The counterfactual then requires counterfactual reasoning about those beings fulfilling the contextual restriction.

In both cases (indicative and counterfactual conditionals), the conditional involves projecting oneself directly onto a general and possibly counterfactual situation and seeing what the outcome is.

With counterfactual conditionals, one can see nicely the difference between simulation, as in (69a), and a strategy quite distinct from simulation, namely 'using oneself as a model' (cf. Gordon, 1995b), as in (69b):

(69)a. If I were you, I would hate me.

b. If I were like you, I would hate me.

With $I$ in (69a) the speaker does not refer to himself, but rather, in a pretend way, to the addressee-he simulates the addressee. By contrast, in (69b), I acts, as usual, as a rigid designator, referring to the speaker who compares himself, in a counterfactual situation, with the addressee.

Let me conclude with a further remark about the first-person orientation of generic one in conditionals. As with Strategy 1, conditionals with generic one express a generalization on the basis of the first person, but now the first person is involved in a generalizing inference, rather than a first-person experience. With generic one-sentences, the agent pretends to meet the condition expressed by the antecedent and then sees whether he also meets the condition expressed by the consequent. Unlike in sentences using Strategy 1, generic one in conditionals is not a required choice: an indefinite like someone or a person in the antecedent and a definite pronoun in the consequent would have the same overall effect, on both truth and use conditions. Using generic one just allows verifying a conditional in a particular way: on the basis of inference involving the first person, a generalizing first-person inference. What is crucial for the use of one in conditionals thus is the recognition that an inference involving the agent himself is generalizable, rather than, as in the case of Strategy 1, the recognition that a particular kind of experience is generalizable. The same generalizing inference, though, could have been made on the basis of an arbitrarily chosen third person, and hence the nearequivalence of conditional one-sentences with one-sentences involving indefinites such as someone.

\section{Summary}

The general idea of the account of generic one (as well as arbitrary PRO) that I have proposed is that with a generic one-sentence, an agent ascribes a property to each one in the domain 'as if' to himself, that is, while projecting himself onto everyone in the domain. The formal account itself, though, simply specifies that generic one introduces a complex variable consisting of a simple variable to be bound by a generic operator and a the property of being identical to the relevant agent. Whereas, roughly, the first component is responsible for the truth conditions of generic one-sentences, the second component is responsible for the particular connections of generic one to the first person, its first-person orientation. 
We have seen that the ascription of a property 'as if to oneself' can be achieved by using three different strategies, which underlie the use of generic one-sentences for three different purposes:

1. The speaker describes a particular experience (or a particular frequency of experiences) which he recognizes as generalizable, abstracting from particularities of his own situation.

2. The speaker presents an internalized generalization (obligation, permission, general knowledge) which should play a role in his or rather the addressee's practical reasoning, or else the speaker presents the conclusion of a practical syllogism with such a generalization as premise.

3. The speaker, abstracting from the particularities of his own situation, ascribes a property to himself on the basis of inference, which as such is generalizable.

One not unimportant feature of one in English, as well as corresponding expressions in other languages, is that one exhibits a great variability in appropriateness among different uses. For example in British English, one is used basically as described in this paper, though some uses of one are considered upper class. In American English one, in what seem to be most uses, tends to be replaced by you, or perhaps we or $I$. As already stated in the introduction, the focus of this paper was not to give an analysis of British English one as such, but to describe a form of first-person-oriented genericity that can potentially associate itself with a variety of expressions.

The semantics of generic one thus involves a general strategy of first-personoriented genericity that can associate itself with different kinds of expressions in a language and across languages and can even just constitute the intended pragmatic effect of the use of an expression in a particular context.

One is an expression that has been widely neglected in both the semantic literature and in the literature in philosophy of language. This may have been so because one involves concepts outside the usual arsenal of formal semantics, namely notions much more familiar from discussions in philosophy of mind and cognitive science. At the same time, one is an expression whose use is essential in the discourse of the latter disciplines themselves, a fact that perhaps does not necessarily invite a philosophical examination either. This paper has made a first proposal of how the various philosophically interesting properties of one can be accounted for semantically in a unified way.

\section{References}

Carlson, G. (1995). Truth-conditions of generic sentences: Two contrasting views. In G. N. Carlson, \& F. J. Pelletier (Eds.), The generic book (pp. 224-237). Chicago: University of Chicago Press. Castaneda, H.-N. (1966). He*: A study in the logic of self-consciousness. Ratio, 8, 130-157.

Castaneda, H.-N. (1967). The logic of self-attributions to others. American Philosophical Quarterly, 4, 85-100.

Chierchia, G. (1990). Anaphora and attitudes De Se. In R. Bartsch et al. (Eds.), Language in action (pp. 1-31). Dordrecht: Foris Publications.

Chierchia, G. (1995). The variability of impersonal subjects. In E. Bach et al. (Eds.), Quantification in natural language (pp. 107-143). Dordrecht: Kluwer Academic Publishers.

Chomsky, N. (1980). On binding. Linguistic Inquiry, 11(1), 1-46.

Cohen, A. (1999). On the generic use of indefinite singulars. Journal of Semantics, 18(3), 183-209. 
Evans, G. (1982). Self-identification. In J. McDowell (Ed.), Varieties of reference (pp. 205-233). Oxford: Oxford University Press.

Fodor, J. (1975). The language of thought. Ithaca, NY: Cornell University Press.

Forbes, G. (1997). How much substitutivity? Analysis, 57(2), 109-113.

Gaerdenfors, P. (1986). Belief revision and the Ramsey test for conditionals. Philosophical Review, 95, 81-93.

Giorgi, A., \& Longobardi, P. (1991). The syntax of noun phrases: Configuration, parameters, and empty categories. Cambridge: Cambridge University Press.

Goldman, A. I. (1989). Interpretation psychologized. Mind and Language, 4, 161-185.

Goldman, A. I. (1995). In defense of simulation theory. In M. Davies, \& T. Stone (Eds.), Mental simulation: Evaluation and applications. Oxford: Blackwell.

Gordon, R. M. (1986). Folkpsychology as simulation. Mind and Language, 1, 158-171.

Gordon, R. M. (1995a). The simulation theory: Objections and misconceptions. In M. Davies, \& T. Stone (Eds.), Mental simulation: Evaluation and applications. Oxford: Blackwell.

Gordon, R. M. (1995b). Simulation without introspection or inference from me to you. In M. Davies, \& T. Stone (Eds.).

Heal, J. (1986). Replication and functionalism. In J. Butterfield (Ed.), Language, mind, and logic. Cambridge: Cambridge University Press.

Heim, I. (1982). The semantics and definite and indefinite noun phrases. PhD dissertation, University of Massachusetts at Amherst.

Higginbotham, J. (2003). Remembering, imagining, and the first person. In A. Barber (Ed.), Epistemology of language (pp. 496-533). Oxford: Oxford University Press.

Kadmon, N. \& Landman, F. (1993). Any. Linguistics and Philosophy, 16, 355-422.

Kamp, H. (1981). A theory of truth and representation. In J. Groenendijk et al. (Eds.), Truth, interpretation and information (pp. 277-322). Dordrecht: Foris.

Kratzer, A. (1998). More structural analogies between pronouns and tense. In D. Strolovitch, \& A. Lawson (Eds.), Proceedings of SALT 8 (pp. 92-110). Ithaca, NY: CLC Publications.

Kratzer, A. (2006). Indefinites and the operators they depend on: From Japanese to Salish. In G. N. Carlson, \& F. J. Pelletier (Eds.), Reference and quantification. The Partee effect. Stanford: CSLI Publications.

Krifka, M., Pelletier, F. J., Carlson, G. N., ter Meulen, A., Chierchia, G., \& Link, G. (1995). Genericity. An introduction. In G. N. Carlson, \& F. J. Pelletier (Eds.), The generic book. Chicago: Chicago University Press.

Lewis, D. (1975). Adverbs of quantification. In E. Keenan (Ed.), Formal semantics of natural language (pp. 3-15). Cambridge: Cambridge University Press.

Lewis, D. (1979). Attitudes De Dicto and De Se. The Philosophical Review, 88, 513-543.

Perry, J. (1996). The self. In Routledge Encyclopedia of Philosophy.

Ramsey, F. P. (1931). General propositions and causality. In The foundations of mathematics (pp. 237-255). London: Routledge and Kegan.

Recanati, F. (2002). Varieties of simulation. In J. Dokic, \& J. Proust (Eds.), Simulation and knowledge of action (pp. 151-171). Amsterdam: John Benjamins.

Rosenthal, D. (2003). Unity of consciousness and the self. Proceedings of the Aristotelian Society, 23(3), 325-352.

Safir, K. (2000). Keeping one's reference constant, Manuscript, Rutgers University.

Saul, J. (1997). Substitution and simple sentences. Analysis, 57(2), 102-108.

Shoemaker, S. (1968). Self-reference and self-awareness. Journal of Philosophy, 65(19), 555-567. 